\title{
Radiographic Results on Acetabular Cup Placement with the SuperPath Technique: A Retrospective Study of 756 Cases
}

Agostino Di Maro ( $\square$ agostino.dimaro88@gmail.com )

Ospedale di Circolo di Busto Arsizio

\section{Santo Creaco}

Ospedale di Circolo di Busto Arsizio

Mattia Albini

Ospedale di Circolo e Fondazione Macchi

Mahfuz Latiff

Ospedale di Circolo e Fondazione Macchi

Marco Merlo

Ospedale di Circolo di Busto Arsizio

\section{Research Article}

Keywords: Radiographic results, acetabular cup placement, Supercapsular percutaneously , total hip arthroplasty (THA)

Posted Date: October 22nd, 2021

DOI: https://doi.org/10.21203/rs.3.rs-952471/v1

License: (c) (i) This work is licensed under a Creative Commons Attribution 4.0 International License. Read Full License 


\section{Abstract}

\section{Background}

The Supercapsular percutaneously assisted total hip (SuperPath) technique is a relatively new minimally invasive approach for total hip arthroplasty (THA). Good clinical outcomes related to its use are reported in the literature. Nonetheless, there are still uncertainties about its validity in terms of radiographic outcomes.

Purposes of the study are to evaluate the effectiveness of the SuperPath in acetabular cup positioning through radiographic evaluation of acetabular inclination angle (IA) and acetabular anteversion (AA) angle within the safe zone described by Lewinnek; to investigate cases of hip dislocation; to evaluate whether our results differ from those reported in recent literature; to evaluate whether there was a statistically significant radiographic difference in acetabular cup placement between two consecutive years.

Methods

Between January 2016 and December 2019, all SuperPath cases eligible for the study were included. They were operated by three Orthopaedic surgeons with long-standing experience in THA via traditional posterolateral approach and who have performed SuperPath training fellowship. The results were analyzed by statistical analysis.

Results

A retrospective analysis of 756 THAs was performed. Means \pm standard deviation (SD) of the radiographic IA and AA were calculated for each year. The average percentage of IA within the Lewinnek's safe zone was from $80 \%$ to $85 \%$, while the average percentage of AA was from $76 \%$ to $79 \%$. Both IA and AA showed no statistically significant difference between two consecutive years. So, there was no statistically significant improvement regarding the radiographic values between two consecutive years for both IA and AA. There were only two cases of hip dislocations. The radiographic values were similar to recent data in the literature from authors using SuperPath and comparing their results with classical surgical approaches.

\section{Conclusion}

It is possible to achieve good radiographic values of acetabular cup orientation through the SuperPath within the Lewinnek's safe zone. These results are similar to those reported in the literature by authors using SuperPath. Low rate $(0,3 \%)$ of hip dislocations were reported. Therefore, the SuperPath technique represents a good alternative for THA. Nevertheless, there is not a statistically significant improvement in these radiographic parameters over a four-year time.

Level of Evidence: Level IV, retrospective study. 


\section{Introduction}

The correct placement of the acetabular cup in total hip arthroplasty (THA) surgery is associated with better clinical outcomes and a lower complication rate [1-8]. Several surgical approaches for THA were developed with the goal of gaining better exposure for placing the acetabular component correctly and safely in all orientations $[9,10]$. In addition, a wide variety of surgical minimally invasive (MIS) approaches have gained popularity among Orthopaedic surgeons with the aim of obtaining simultaneous satisfactory clinical-radiographic results and greater muscles sparing during the surgical approach [1114]. Nevertheless, some MIS techniques were associated with higher rates of component malposition, ascribing to a reduced visualization of the acetabulum compared with standard procedures [15-20]. Among the several MIS, the Supercapsular percutaneously assisted total hip (SuperPath) (MicroPort Orthopedics Inc., Arlington, TN, USA) is a minimally invasive technique that utilizes a muscle-sparing surgical approach between the piriformis and gluteus minimus muscles, preserving the insertion of the extrarotator muscles, the posterior capsule, and avoiding surgical dislocation of the femoral head [21]. It is particularly successful and several benefits were attributed to its use such as tissues preservation, early postoperative recovery from the pain, short incision length, short hospitalization, early recovery of daily activities, less perioperative blood loss and a lower transfusion [22-26]. There is not yet a large radiographic case series in the literature regarding acetabular cup placement in THAs via the SuperPath technique.

The purpose of our study is to evaluate the effectiveness of this technique in properly positioning the acetabular cup, through evaluation of the radiographic parameters of the acetabular inclination angle (IA) and the acetabular anteversion angle (AA) of 756 THAs operated in 4 years. The hypothesis of our study is that most cases analyzed have values within the "safe zone" according to Lewinnek, with a good percentage comparable to those obtained using traditional surgical approaches [27]. Lewinnek et al. suggested a "safe zone" of Al of $40^{\circ} \pm 10^{\circ}$ and AA of $15^{\circ} \pm 10^{\circ}$ to minimize the risk of dislocation. We assessed whether there was a statistically significant difference in this regard between two consecutive years. We also retrospectively examined hip dislocation cases operated over 4 years and with mean follow-up of 30,3 months. Finally, looking at the latest studies reported in the literature describing a comparison between SuperPath and traditional surgical approaches, we wanted to assess where our results could fit in.

\section{Materials And Methods}

Between January 2016 and December 2019 at Ospedale di Circolo di Busto Arsizio, ASST Valle Olona (Italy), the SuperPath technique was used for THA implants in a total of 800 patients (856 THAs). The radiographic parameter considered in our study was the IA and the AA. IA was calculated on a standard posteroanterior radiograph, using the horizontal inter-teardrop line and the oblique line passed through the major axis of the acetabular cup [28-30]. AA was measured using a cross-table lateral radiograph, with the angle obtained between the axis of the coronal plane and the axis of the acetabular cup [31, 32]. The mean (in degrees) of the values obtained \pm standard deviation (SD) was then calculated. Patients 
were evaluated with posteroanterior and lateral hip x-rays at 1 month, 3 months, 6 months, and then annually after surgery. The radiographic angles were measured by two authors (M.A. and M.L.) on the postoperative images, evaluating the radiographic images extracted from the General Electric Centricity Picture Archiving and Communication System (PACS). Exclusion criteria were follow-up less than one year, and inadequate radiographic projections for measurement of IA and AA angles [5, 31-33]. Patients included in the study were operated by 3 Orthopaedic surgeons who had several years of experience in hip arthroplasty with the standard postero-lateral approach [33]. They had also performed a fellowship program on the SuperPath technique prior to this study. For each year, we calculated the total number of operated hips, the mean of the IA and AA values $\pm S D$, and the number of radiographic cases (with associated percentage) that fell within Lewinnek's "safe zone". We retrospectively analyzed all radiographic images included in the study for cases of hip dislocations. In addition, it was assessed whether there was a statistically significant improvement or worsening in obtaining the inclination between one year and the following year. The Paired Student t-test was used for statistical assessments, with a p-value $<0.05$ considered statistically significant and reported as two-tailed.

\section{Surgical Technique}

The patient was positioned in a lateral decubitus position, held by appropriate supports, with the hip flexed at $45^{\circ}$ and intrarotated at about $10-15^{\circ}$. After setting up the surgical aseptic field, a direct surgical incision was made at the level of the great trochanter in line with the femoral axis. The fibers of the gluteus maximus muscle were spread with a Zelpi retractor. The muscle interval between the gluteus medius and piriformis was reached, capsulotomy was performed in line with the femoral neck, and surgical exposure at that level was maintained using a Romanelli retractor. The femoral canal was reamed using the trochanteric fossa as a reference point (with the starting point of the reaming anterior to the trochanteric fossa) and using a canal feeler to optimally ensure the location of the femoral canal itself. Progressive broaches were used, with the last of them left inside the femur and checked with intraoperative $\mathrm{X}$-rays to assess the exact position. With the last broach into the femoral canal, used as a guide, the femoral neck was cut and the head was extracted with a Schanz pin. A Zelpi retractor subperiosteally and a Romanelli retractor intraarticularly were used for the acetabulum visualization, an Alignment Handle and a Portal Placement Guide were used so that the top of the guide was perpendicular to the patient's torso, and the shaft of the guide was tilted approximately $10-15^{\circ}$ from vertical to assess pelvic tilt on the operating table. At the point of the intersection of the Blunt Trocar with the leg, a miniincision of about $1 \mathrm{~cm}$ was made posterior to the proximal third of the femoral diaphysis and the cannula for the acetabular reamer drive shaft was introduced, just posterior to the trochanter as planned for the acetabular placement. The acetabulum was reamed with progressive reamers and then the trial acetabular component was inserted. Trial heads and necks were used according to the preoperative planning, to obtain adequate length of the lower limbs between them and stability of the prosthetic components. After choosing the size of the prosthetic components, the trials were removed, and the definitive components were implanted, ultimately considering visual anatomical landmarks such as the native acetabular version and the transverse acetabular ligament. Final hip maneuvers were performed to 
assess the final stability of the prosthetic implant. After lavage with saline solution, suturing was performed by anatomical layers [21, 35].

\section{Results}

Out of 800 hips operated, 44 were excluded. A total of 756 hips (700 patients) were enrolled in this study, from January 2016 to December 2019, of whom 341 were male and 359 were female. Thirty-seven patients were operated on both hips, of whom 12 were operated in a single surgical step (single anesthetic), while the remaining 25 patients were operated in two different surgical steps (two separate anesthetic). The mean age at the time of surgery was 71 years (range, 26-104 years). The age of patients operated on both hips was calculated twice at the time of the surgery. The diseases from which the patients were affected were as follows: primary hip osteoarthritis (454 hips), secondary osteoarthritis (100 hips), femoral head avascular necrosis (70 hips), developmental hip dysplasia (29 hips), and femoral neck fracture (103 hips). During the year 2016, 164 hips were operated, in 2017 they were 203, in 2018 they were 188 hips, and in 2019 they were 201.

Table 1 summarizes the main patients' demographics. 
Table 1

Patients' demographics.

\begin{tabular}{|ll|}
\hline \multicolumn{2}{|l|}{ Demographic charateristics of the patients } \\
\hline Total number of patients & 700 \\
\hline Male & 341 \\
\hline Female & 359 \\
\hline Mean age at time of surgery (range) & $71(26-104)$ \\
\hline Total hips & 756 \\
\hline Primary Hip Osteoarthtritis & 454 \\
\hline Secondary Hip Osteoarthtritis & 100 \\
\hline Femural Head Avascular Necrosis & 70 \\
\hline Developmental Dysplasia of the Hip & 29 \\
\hline Femural Neck Fracture & 103 \\
\hline Year & Number of hips \\
\hline 2016 & 164 \\
\hline 2017 & 203 \\
\hline 2018 & 188 \\
\hline 2019 & 201 \\
\hline
\end{tabular}

In 2016 the average IA was $39^{\circ} \pm 8,3$; in 2017 the average was 42,9 $\pm 8,3$; in 2018 it was $45^{\circ} \pm 8$; in 2019 the IA was $43,1^{\circ} \pm 7,3$. The overall average for all years was $42,7^{\circ} \pm 8,2$. In addition, in the year $2016,80 \%$ of the hips operated on were within Lewinnek's "safe zone" limits; in 2017 that percentage was 82\%; in 2018 it was $81 \%$; in 2019 it was $85 \%$. The average percentage of hips within Lewinnek's target zone during the period analyzed was $82 \%$. It was found that there was not a statistically significant difference in IA values between one year and the subsequent year ( $p$-value 2016 vs $2017=0,5$; p-value 2017 vs 2018 $=0,9 ; p$-value 2018 vs $2019=0,8)$. Tables 2 and 3 summarize the results obtained. 
Table 2

Results of IA.

\begin{tabular}{|lllll|}
\hline Years & $\begin{array}{l}\text { Anteversion angle mean }\left(^{\circ}\right) \pm \\
\text { SD (range) }\end{array}$ & $\begin{array}{l}\text { Number (\%) of hips within the } \\
\text { Lewinnek safe zone }\end{array}$ & p-value & \\
\hline 2016 & $39 \pm 8,3(18,2-63,6)$ & $132(80)$ & 2016 vs & 0,5 \\
\hline 2017 & $42,9 \pm 8,3(21,7-63,8)$ & $166(82)$ & 2017 & \\
\hline 2018 & $45 \pm 8(22-68,8)$ & $152(81)$ & 2017 vs & 0,9 \\
2019 & $43,1 \pm 7,3(26,3-62,3)$ & $170(85)$ & 2018 & \\
2016 to & $42,7 \pm 8,2(18,2-68,8)$ & $620(82)$ & 2018 vs & 0,8 \\
2019 & & & 2019 & \\
\hline
\end{tabular}

Table 3

Results of AA.

\begin{tabular}{|lllll|}
\hline Years & $\begin{array}{l}\text { Inclination angle mean }\left(^{\circ}\right) \pm \\
\text { SD (range) }\end{array}$ & $\begin{array}{l}\text { Number (\%) of hips within the } \\
\text { Lewinnek safe zone }\end{array}$ & p-value & \\
\hline 2016 & $20,2 \pm 6,7(10,1-40)$ & $125(76)$ & 2016 vs & 0,4 \\
\hline 2017 & $15,3 \pm 7,1(5,4-51,2)$ & $152(75)$ & 2017 & \\
\hline 2018 & $17,9 \pm 8(9,8-59,3)$ & $149(79)$ & 2017 vs & 0,7 \\
\hline 2019 & $16,1 \pm 5,8(10,5-44,6)$ & $157(78)$ & 2018 & \\
\hline 2016 to & $17,6 \pm 3,2(5,4-59,3)$ & $583(77)$ & 2018 vs & 0,6 \\
\hline 2019 & & & 2019 & \\
\hline
\end{tabular}

The average AA values obtained were $20,2^{\circ} \pm 6,7$ in 2016 ; average values of $15,3^{\circ} \pm 7,1$ in 2017; average values of $17,9^{\circ} \pm 8$ in 2018 ; and average values of $16,1^{\circ} \pm 5,8$ in 2019 . The average $A A$ value over the 4 years was $17,6^{\circ} \pm 3,2$. The average annual percentage of hips in the Lewinnek safe zone were: $76 \%$ in $2016 ; 75 \%$ in 2017; 79\% in 2018; and 78\% in 2019. The average percentage from 2016 to 2019 was $77 \%$.

As with IA, we found no statistically significant differences between two consecutive years for AA: $p$-value 2016 vs $2017=0,4$; p-value 2017 vs $2018=0,7$; p-value 2018 vs $2019=0,6$. We also assessed whether there was a statistically significant difference between the first and last years for both IA and AA: it was not present for either ( $p$-value 2016 vs 2019 for IA: 0,7; p-value 2016 vs 2019 for AA: 0,6).

In the x-rays analysis, in a mean follow-up of 30,3 months, we only encountered two cases of hip dislocation operated in 2016, approximately 6 and 8 months after surgery.

\section{Discussions}


Malposition of the acetabular cup is associated with complications such as impingement, recurrent dislocation, increased ischial osteolysis and wear of prosthetic components [36-38]. Few studies have evaluated acetabular cup placement depending on the surgical approach [29, 39-41]. MIS techniques arose with the simultaneous effort to reduce periarticular tissue damage and achieve good clinicalradiographic results, the latter at least overlapping with those obtained with traditional surgical approaches [42-44]. In this regard, it would also be appropriate to clarify the correct definition of MIS, since the surgical approaches are manifold and different from each other. This is not the aim of our study, but it would at least provide a better understanding of SuperPath in that framework. Controversies exist over the precise definition of a minimally invasive approach, as no clear definition is reported [22, 37, 45]. The SuperPath technique fits into the group of minimally invasive muscle-sparing techniques, since it preserves the cutting of the extrarotator muscles, hip joint capsule, and avoids surgical dislocation of the femoral head [43]. Several studies report benefits related to this technique. Cost-saving benefits associated with the use of the SuperPath were also shown by Gofton et al., as a $28 \%$ reduction in inhospital costs was reported compared with the standard lateral surgical approach [46]. Della Torre et al. reported good radiographic results within Lewinnek's safe zone, as a mean IA of $40,13^{\circ} \pm 6,30$ was obtained from 66 postoperative radiographs [21]. Several criticisms were made towards different MIS regarding the correct placement of the acetabular cup, due to not always clear surgical visualization of the acetabulum $[15,18,42,47]$. Our results claim that the minimally invasive SuperPath technique allows for satisfactory acetabular cup positioning, with an average IA of $42,7^{\circ} \pm 8.2$ (an average of $82 \%$ cases over 4 years in the Lewinnek safe zone), and an average AA of $17,6^{\circ} \pm 3,2$ (an average of $77 \%$ cases over 4 years in the Lewinnek safe zone) in a total of 756 radiographic cases. We inspected the radiographic results of acetabular cup placement reported in the literature by authors comparing SuperPath with traditional surgical approaches. In the systematic review and meta-analysis by Ramadanov et al., 80 patients operated by SuperPath technique and 80 patients operated by conventional approaches, collected from 4 randomized controlled trials, were evaluated. The results of this study showed no difference regarding the acetabular cup placement [22]. Specifically, Xie et al. compared the radiographic acetabular cup placement of 46 cases with primary hip osteoarthritis through the SuperPath technique with that obtained from 46 cases with the same disease through the conventional posterior approach, noting no statistically significant difference between them. In the SuperPath group, the mean IA was $43,6^{\circ}$ $\pm 6,8$, while the mean AA was $17,4^{\circ} \pm 1,6$. In the conventional posterior approach group, the mean IA was $44,5^{\circ} \pm 6,5$, while the mean AA was $18,5^{\circ} \pm 1,8$ [23]. Ouyang et al. reported in a randomized controlled trial of 24 cases of THAs, 12 operated with the SuperPath and 12 operated with the posterolateral approach, the following radiographic findings of $I A$ and $A A$ : mean $I A$ of $37,08^{\circ} \pm 6,53$ and mean $A A$ of $21,92^{\circ} \pm 5,78$ in the SuperPath group, while mean IA of $39,67^{\circ} \pm 6,95$ and mean $A A$ of $21,75^{\circ} \pm 4,48$ in the conventional group [48]. Meng et al. in their recent study of 2020, where they evaluated 4 patients with bilateral femoral head osteonecrosis operated with SuperPath technique on one side and with the postero-lateral approach on the other side, found lower values of IA in SuperPath $\left(38,75^{\circ} \pm 8,21\right)$ than the control group $\left(44,50^{\circ} \pm\right.$ $3,64)$, and they are also lower than our values. Regarding AA, the authors obtained values of $15,00^{\circ} \pm$ 1,82 , similar to those obtained by us [49]. A statistically lower result of IA with SuperPath compared to the use of posterolateral mini-incision approach was obtained by another work of Meng et al., where in 20 
patients operated for THA with SuperPath they found an IA value of $36,94^{\circ} \pm 6,37$, while in the control group it was $42,66^{\circ} \pm 3,58$ ( $p$-value $=0,004$ ). On the other hand, there was no statistically significant difference in mean AA values (SuperPath, mean AA of $13,94^{\circ} \pm 4,73$; posterolateral approach, mean AA value of $15,11^{\circ} \pm 4,06$ ) [43]. However, from both papers by Meng et al., both IA and $A A$ values were within the Lewinnek safe zone. On the other hand, Tottas et al. reported, in a group of 40 patients, IA values with SuperPath statistically higher than mean IA values obtained with the Hardinge approach $\left(51,2^{\circ} \pm 4,8\right.$ vs $43,7^{\circ} \pm 4,4$, respectively); while statistically similar values were found in the two groups regarding $A A$ $\left(20,5^{\circ} \pm 9,8\right.$ in the SuperPath group vs $25,0^{\circ} \pm 7,9$ in the Hardinge approach group) [50]. With respect to the previous work cited, Kay et al. analyzed, in addition to the mean values of IA and AA, a 2-year followup regarding the evaluation of dislocations of THAs (zero dislocations reported). The mean IA value obtained was $43,6^{\circ} \pm 5,2$ and the mean AA value was $20,9^{\circ} \pm 6,2$ [51]. Evaluating the above IA and AA values of these authors, our results show substantially similarities. We obtained IA and AA values of a large case series (756 cases) satisfactory regarding the safe zone proposed by Lewinnek, with a low number of hip dislocations $(0,3 \%)$, moreover in the first year of the study. In addition, analyzing the averages of inclination angle across years, it was noted that there was no statistically significant improvement with increased surgical experience with the SuperPath technique. This finding can be interpreted in two ways: the learning curve for obtaining a good cup placement does not require few years to obtain satisfactory radiographic results; conversely, with the SuperPath technique, a statistically better result cannot be achieved in a 4-year period, even with increased surgical experience. This confuted the second hypothesis of our study.

Our study has a few limitations, such as the retrospective nature of the results, lack of randomization between Orthopaedic surgeons and operated patients, lack of a control group with traditional surgical approach, additional clinical information of patients (e.g., BMI, postoperative lower limb dysmetria). In addition, there is no correlation between radiographic and several clinical results in our study, but this was not the aim of our study, and the numerous benefits of SuperPath in clinical terms were already reported in the literature $[21,23,24,34,52]$.

\section{Conclusions}

The SuperPath technique allows to obtain in experienced surgeons of traditional postero- lateral approach, who underwent Fellowship of this muscle sparing technique, satisfactory radiographic results of acetabular cup placement in THA, with a low rate of hip dislocation. It does not take many years to achieve such results. These results are statistically consistent over a 4-year period. Further studies with more cases and longer follow-up are needed, to further investigate the validity of the SuperPath technique in a more comprehensive clinical-radiographic fashion.

\section{Abbreviations}

SuperPath: Supercapsular percutaneously assisted total hip; THA: total hip arthroplasty; IA: inclination angle; AA: acetabular anteversion; SD: standard deviation; MIS: surgical minimally invasive; PACS: Picture 


\section{Declarations}

\section{Ethics approval and consent to participate}

The experimental protocols were approved by the commission of the Department of Clinical and Experimental Medicine of the University of Insubria in Varese. All methods were used in accordance with the valid regulations of the competent regulatory authority. Informed consent was obtained from all participants.

\section{Consent for publication}

Not applicable.

\section{Availability of data and material}

The datasets used and/or analysed during the current study are not publicly available because they are deemed essential for use in further studies in the future, but they are available from the corresponding author on reasonable request.

\section{Competing interests}

All authors have no financial disclosures.

\section{Authors' contributions}

ADM: Data collection, manuscript preparation. SC: Manuscript preparation. MA: Data collection. ML: Data collection, table creation. MM: Senior author, performed part of surgeries, manuscript editing. All authors have read and approved this manuscript.

\section{References}

1. Callanan MC, Jarrett B, Bragdon CR, Zurakowski D, Rubash HE, Freiberg AA, Malchau H. The John Charnley Award: risk factors for cup malpositioning: quality improvement through a joint registry at a tertiary hospital. Clin Orthop Relat Res. 2011 Feb;469(2):319-29. doi: 10.1007/s11999-010-1487-1. PMID: 20717858; PMCID: PMC3018230. 
2. Kennedy JG, Rogers WB, Soffe KE, Sullivan RJ, Griffen DG, Sheehan LJ. Effect of acetabular component orientation on recurrent dislocation, pelvic osteolysis, polyethylene wear, and component migration. J Arthroplasty. 1998 Aug;13(5):530-4. doi: 10.1016/s0883-5403(98)90052-3. PMID: 9726318.

3. Tannast M, Langlotz U, Siebenrock KA, Wiese M, Bernsmann K, Langlotz F. Anatomic referencing of cup orientation in total hip arthroplasty. Clin Orthop Relat Res. 2005 Jul;(436):144-50. doi: 10.1097/01.blo.0000157657.22894.29. PMID: 15995433.

4. Hirakawa K, Mitsugi N, Koshino T, Saito T, Hirasawa Y, Kubo T. Effect of acetabular cup position and orientation in cemented total hip arthroplasty. Clin Orthop Relat Res. 2001 Jul;(388):135-42. doi: 10.1097/00003086-200107000-00020. PMID: 11451112.

5. Kadar T, Furnes O, Aamodt A, Indrekvam K, Havelin LI, Haugan K, Espehaug B, Hallan G. The influence of acetabular inclination angle on the penetration of polyethylene and migration of the acetabular component: a prospective, radiostereometric study on cemented acetabular components. J Bone Joint Surg Br. 2012 Mar;94(3):302-7. doi: 10.1302/0301-620X.94B3.27460. PMID: 22371534.

6. Korhonen RK, Koistinen A, Konttinen YT, Santavirta SS, Lappalainen R. The effect of geometry and abduction angle on the stresses in cemented UHMWPE acetabular cups--finite element simulations and experimental tests. Biomed Eng Online. 2005 May 17;4:32. doi: 10.1186/1475-925X-4-32. PMID: 15904521; PMCID: PMC1173123.

7. Patil S, Bergula A, Chen PC, Colwell CW Jr, D'Lima DD. Polyethylene wear and acetabular component orientation. J Bone Joint Surg Am. 2003;85-A Suppl 4:56-63. doi: 10.2106/00004623-20030000400007. PMID: 14652394.

8. Zhao JX, Su XY, Zhao Z, Xiao RX, Zhang LC, Tang PF. Radiographic assessment of the cup orientation after total hip arthroplasty: a literature review. Ann Transl Med. 2020 Feb;8(4):130. doi: 10.21037/atm.2019.12.150. Erratum in: Ann Transl Med. 2020 May;8(10):657. PMID: 32175423; PMCID: PMC7049040.

9. Barrack RL, Krempec JA, Clohisy JC, McDonald DJ, Ricci WM, Ruh EL, Nunley RM. Accuracy of acetabular component position in hip arthroplasty. J Bone Joint Surg Am. 2013 Oct 2;95(19):1760-8. doi: 10.2106/JBJS.L.01704. PMID: 24088968.

10. Myers GJ, Morgan D, McBryde CW, O'Dwyer K. Does surgical approach influence component positioning with Birmingham Hip Resurfacing? Int Orthop. 2009 Feb;33(1):59-63. doi:

10.1007/s00264-007-0469-8. Epub 2007 Oct 30. PMID: 17968547; PMCID: PMC2899254.

11. Dorr LD, Maheshwari AV, Long WT, Wan Z, Sirianni LE. Early pain relief and function after posterior minimally invasive and conventional total hip arthroplasty. A prospective, randomized, blinded study. J Bone Joint Surg Am. 2007 Jun;89(6):1153-60. doi: 10.2106/JBJS.F.00940. PMID: 17545416.

12. Levine BR, Klein GR, Di Cesare PE. Surgical approaches in total hip arthroplasty: a review of the miniincision and MIS literature. Bull NYU Hosp Jt Dis. 2007;65(1):5-18. PMID: 17539756.

13. Mayr E, Nogler M, Benedetti MG, Kessler O, Reinthaler A, Krismer M, Leardini A. A prospective randomized assessment of earlier functional recovery in THA patients treated by minimally invasive 
direct anterior approach: a gait analysis study. Clin Biomech (Bristol, Avon). 2009 Dec;24(10):812-8. doi: 10.1016/j.clinbiomech.2009.07.010. Epub 2009 Aug 21. PMID: 19699566.

14. Mazoochian F, Weber P, Schramm S, Utzschneider S, Fottner A, Jansson V. Minimally invasive total hip arthroplasty: a randomized controlled prospective trial. Arch Orthop Trauma Surg. 2009 Dec;129(12):1633-9. doi: 10.1007/s00402-009-0870-4. Epub 2009 May 8. PMID: 19424709.

15. Berry DJ, Berger RA, Callaghan JJ, Dorr LD, Duwelius PJ, Hartzband MA, Lieberman JR, Mears DC. Minimally invasive total hip arthroplasty. Development, early results, and a critical analysis. Presented at the Annual Meeting of the American Orthopaedic Association, Charleston, South Carolina, USA, June 14, 2003. J Bone Joint Surg Am. 2003 Nov;85(11):2235-46. PMID: 14630860.

16. Goyal P, Lau A, McCalden R, Teeter MG, Howard JL, Lanting BA. Accuracy of the modified Hardinge approach in acetabular positioning. Can J Surg. 2016 Aug;59(4):247-53. doi: 10.1503/cjs.011415. PMID: 27240130; PMCID: PMC4961487.

17. Lilikakis $A K$, Villar RN. The influence of incision length on immediate postoperative rehabilitation after total hip replacement. Hip Int. 2005 Apr-Jun;15(2):102-107. doi: 10.5301/HIP.2008.1772. PMID: 28224565.

18. Mardones R, Pagnano MW, Nemanich JP, Trousdale RT. The Frank Stinchfield Award: muscle damage after total hip arthroplasty done with the two-incision and mini-posterior techniques. Clin Orthop Relat Res. 2005 Dec; 441:63-7. doi: 10.1097/01.blo.0000194727.55372.04. PMID: 16330985.

19. Mouilhade F, Matsoukis J, Oger P, Mandereau C, Brzakala V, Dujardin F. Component positioning in primary total hip replacement: a prospective comparative study of two anterolateral approaches, minimally invasive versus gluteus medius hemimyotomy. Orthop Traumatol Surg Res. 2011 Feb;97(1):14-21. doi: 10.1016/j.otsr.2010.05.013. Epub 2011 Jan 13. PMID: 21236746.

20. Nakamura S, Matsuda K, Arai N, Wakimoto N, Matsushita T. Mini-incision posterior approach for total hip arthroplasty. Int Orthop. 2004 Aug;28(4):214-7. doi: 10.1007/s00264-004-0570-1. Epub 2004 May 28. PMID: 15168084; PMCID: PMC3456936.

21. Della Torre PK, Fitch DA, Chow JC. Supercapsular percutaneously-assisted total hip arthroplasty: radiographic outcomes and surgical technique. Ann Transl Med. 2015 Aug;3(13):180. doi: 10.3978/j.issn.2305-5839.2015.08.04. PMID: 26366397; PMCID: PMC4543328.

22. Ramadanov N, Bueschges S, Liu K, Klein R, Schultka R. Comparison of short-term outcomes between SuperPATH approach and conventional approaches in hip replacement: a systematic review and meta-analysis of randomized controlled trials. J Orthop Surg Res. 2020 Sep 17;15(1):420. doi: 10.1186/s13018-020-01884-3. PMID: 32943082; PMCID: PMC7499876.

23. Xie J, Zhang H, Wang L, Yao X, Pan Z, Jiang Q. Comparison of supercapsular percutaneously assisted approach total hip versus conventional posterior approach for total hip arthroplasty: a prospective, randomized controlled trial. J Orthop Surg Res. 2017 Sep 25;12(1):138. doi: 10.1186/s13018-017-0636-6. PMID: 28946892; PMCID: PMC5613398.

24. Gofton W, Chow J, Olsen KD, Fitch DA. Thirty-day readmission rate and discharge status following total hip arthroplasty using the supercapsular percutaneously-assisted total hip surgical technique. 
Int Orthop. 2015 May;39(5):847-51. doi: 10.1007/s00264-014-2587-4. Epub 2014 Nov 16. PMID: 25398472.

25. Hu Y, Wang MC, Wang T, Meng Y, Chao XM, Zhu HF, Li CG, Pan CL, He HB. Less blood loss in supercapsular percutaneously assisted versus posterolateral total hip arthroplasty. J Orthop Surg Res. 2021 Mar 25;16(1):217. doi: 10.1186/s13018-021-02363-z. PMID: 33766085; PMCID: PMC7992970.

26. Lei P, Liao Z, Peng J, Li G, Zhou Q, Xiao X, Yang C. Assessment of the Learning Curve of Supercapsular Percutaneously Assisted Total Hip Arthroplasty in an Asian Population. Biomed Res Int. 2020 Sep 7;2020:5180458. doi: 10.1155/2020/5180458. PMID: 32964033; PMCID: PMC7492896.

27. Lewinnek GE, Lewis JL, Tarr R, Compere CL, Zimmerman JR. Dislocations after total hip-replacement arthroplasties. J Bone Joint Surg Am. 1978 Mar;60(2):217-20. PMID: 641088.

28. Meermans G, Malik A, Witt J, Haddad F. Preoperative radiographic assessment of limb-length discrepancy in total hip arthroplasty. Clin Orthop Relat Res. 2011 Jun;469(6):1677-82. doi: 10.1007/s11999-010-1588-x. Epub 2010 Sep 29. PMID: $20878559 ;$ PMCID: PMC3094616.

29. Debi R, Slamowicz E, Cohen O, Elbaz A, Lubovsky O, Lakstein D, Tan Z, Atoun E. Acetabular cup orientation and postoperative leg length discrepancy in patients undergoing elective total hip arthroplasty via a direct anterior and anterolateral approaches. BMC Musculoskelet Disord. 2018 Jun 8;19(1):188. doi: 10.1186/s12891-018-2097-4. PMID: 29879934; PMCID: PMC5992835.

30. Seagrave KG, Troelsen A, Malchau H, Husted H, Gromov K. Acetabular cup position and risk of dislocation in primary total hip arthroplasty. Acta Orthop. 2017 Feb;88(1):10-17. doi:

10.1080/17453674.2016.1251255. Epub 2016 Nov 23. PMID: 27879150; PMCID: PMC5251254.

31. Murray DW. The definition and measurement of acetabular orientation. J Bone Joint Surg Br. 1993 Mar;75(2):228-32. doi: 10.1302/0301-620X.75B2.8444942. PMID: 8444942.

32. Jolles $B M$, Zangger $P$, Leyvraz PF. Factors predisposing to dislocation after primary total hip arthroplasty: a multivariate analysis. J Arthroplasty. 2002 Apr;17(3):282-8. doi: 10.1054/arth.2002.30286. PMID: 11938502.

33. Clohisy JC, Carlisle JC, Beaulé PE, Kim YJ, Trousdale RT, Sierra RJ, Leunig M, Schoenecker PL, Millis MB. A systematic approach to the plain radiographic evaluation of the young adult hip. J Bone Joint Surg Am. 2008 Nov;90 Suppl 4(Suppl 4):47-66. doi: 10.2106/JBJS.H.00756. PMID: 18984718; PMCID: PMC2682767.

34. Tang JB, Giddins G. Why and how to report surgeons' levels of expertise. J Hand Surg Eur Vol. 2016 May;41(4):365-6. doi: 10.1177/1753193416641590. PMID: 27076602.

35. Chow J, Penenberg B, Murphy S. Modified micro-superior percutaneously-assisted total hip: early experiences \& case reports. Curr Rev Musculoskelet Med. 2011 Sep;4(3):146-50. doi: 10.1007/s12178-011-9090-y. PMID: 21789576; PMCID: PMC3261255.

36. Hailer NP, Weiss RJ, Stark A, Kärrholm J. The risk of revision due to dislocation after total hip arthroplasty depends on surgical approach, femoral head size, sex, and primary diagnosis. An 
analysis of 78,098 operations in the Swedish Hip Arthroplasty Register. Acta Orthop. 2012 Oct;83(5):442-8. doi: 10.3109/17453674.2012.733919. Epub 2012 Oct 8. PMID: 23039167; PMCID: PMC3488169.

37. Korduba LA, Essner A, Pivec R, Lancin P, Mont MA, Wang A, Delanois RE. Effect of acetabular cup abduction angle on wear of ultrahigh-molecular-weight polyethylene in hip simulator testing. Am $\mathrm{J}$ Orthop (Belle Mead NJ). 2014 Oct;43(10):466-71. PMID: 25303445.

38. Wan Z, Boutary M, Dorr LD. The influence of acetabular component position on wear in total hip arthroplasty. J Arthroplasty. 2008 Jan;23(1):51-6. doi: 10.1016/j.arth.2007.06.008. PMID: 18165028.

39. Moskal JT, Capps SG. Acetabular component positioning in total hip arthroplasty: an evidence-based analysis. J Arthroplasty. 2011 Dec;26(8):1432-7. doi: 10.1016/j.arth.2010.11.011. Epub 2011 Feb 5. PMID: 21296551.

40. Meftah M, Yadav A, Wong AC, Ranawat AS, Ranawat CS. A novel method for accurate and reproducible functional cup positioning in total hip arthroplasty. J Arthroplasty. 2013 Aug;28(7):1200-5. doi: 10.1016/j.arth.2012.09.018. Epub 2013 Feb 23. PMID: 23462497.

41. Soderquist MC, Scully R, Unger AS. Acetabular Placement Accuracy With the Direct Anterior Approach Freehand Technique. J Arthroplasty. 2017 Sep;32(9):2748-2754. doi: 10.1016/j.arth.2017.04.011. Epub 2017 Apr 18. PMID: 28499624.

42. Smith TO, Blake V, Hing CB. Minimally invasive versus conventional exposure for total hip arthroplasty: a systematic review and meta-analysis of clinical and radiological outcomes. Int Orthop. 2011 Feb;35(2):173-84. doi: 10.1007/s00264-010-1075-8. Epub 2010 Jun 18. PMID: 20559827; PMCID: PMC3032108.

43. Meng W, Gao L, Huang Z, Wang H, Wang D, Luo Z, Bai Y, Wang G, Zhou Z. Supercapsular percutaneously-assisted total hip (SuperPath) versus mini-incision posterolateral total hip arthroplasty for hip osteoarthritis: a prospective randomized controlled trial. Ann Transl Med. 2021 Mar;9(5):392. doi: 10.21037/atm-20-1793a. PMID: 33842613; PMCID: PMC8033341.

44. Chow J, Fitch DA. In-hospital costs for total hip replacement performed using the supercapsular percutaneously-assisted total hip replacement surgical technique. Int Orthop. 2017 Jun;41(6):11191123. doi: 10.1007/s00264-016-3327-8. Epub 2016 Nov 12. PMID: 27838761.

45. Oinuma K, Eingartner $\mathrm{C}$, Saito $\mathrm{Y}$, Shiratsuchi $\mathrm{H}$. Total hip arthroplasty by a minimally invasive, direct anterior approach. Oper Orthop Traumatol. 2007 Aug;19(3):310-26. English, German. doi: 10.1007/s00064-007-1209-3. PMID: 17728988.

46. Gofton W, Fitch DA. In-hospital cost comparison between the standard lateral and supercapsular percutaneously-assisted total hip surgical techniques for total hip replacement. Int Orthop. 2016 Mar;40(3):481-5. doi: 10.1007/s00264-015-2878-4. Epub 2015 Jul 9. PMID: 26156723.

47. Yang C, Zhu Q, Han Y, Zhu J, Wang H, Cong R, Zhang D. Minimally-invasive total hip arthroplasty will improve early postoperative outcomes: a prospective, randomized, controlled trial. Ir J Med Sci. 2010 Jun;179(2):285-90. doi: 10.1007/s11845-009-0437-y. Epub 2009 Oct 22. PMID: 19847593. 
48. Ouyang C, Wang H, Meng W, Luo Z, Wang D, Pei F, Zhou Z. [Randomized controlled trial of comparison between the SuperPATH and posterolateral approaches in total hip arthroplasty]. Zhongguo Xiu Fu Chong Jian Wai Ke Za Zhi. 2018 Dec 15;32(12):1500-1506. Chinese. doi: 10.7507/1002-1892.201807011. PMID: 30569673.

49. Meng W, Huang Z, Wang H, Wang D, Luo Z, Bai Y, Gao L, Wang G, Zhou Z. Supercapsular percutaneously-assisted total hip (SuperPath) versus posterolateral total hip arthroplasty in bilateral osteonecrosis of the femoral head: a pilot clinical trial. BMC Musculoskelet Disord. 2019 Dec 31;21(1):2. doi: 10.1186/s12891-019-3023-0. PMID: 31892355; PMCID: PMC6937651.

50. Tottas S, Tsigalou C, Ververidis A, Kougioumtzis IE, Karaglani M, Tilkeridis K, Chatzipapas C, Drosos GI. Supercapsular Percutaneously Assisted total hip arthroplasty versus lateral approach in Total Hip Replacement. A prospective comparative study. J Orthop. 2020 Aug 16;21:406-415. doi: 10.1016/j.jor.2020.08.003. PMID: 32921949; PMCID: PMC7476237.

51. Kay A, Klavas D, Haghshenas V, Phan M, Le D. Two year follow up of supercapsular percutaneously assisted total hip arthroplasty. BMC Musculoskelet Disord. 2021 May 24;22(1):478. doi: 10.1186/s12891-021-04351-0. PMID: 34030681; PMCID: PMC8147097.

52. Cronin MD, Gofton W, Erwin L, Fitch DA, Chow J. Early surgical and functional outcomes comparison of the supercapsular percutaneously-assisted total hip and traditional posterior surgical techniques for total hip arthroplasty: protocol for a randomized, controlled study. Ann Transl Med. 2015 Dec;3(21):335. doi: 10.3978/j.issn.2305-5839.2015.12.15. PMID: 26734645; PMCID: PMC4691001. 